\title{
How to Build a Pay System to Encourage New Generation of Migrant Workers in the Labor Shortage Period
}

\author{
Zhang Zhengjie ${ }^{1}$, Zou Fang $^{1}$ \\ ${ }^{1}$ Sichuan Agricultural University, Chengdu, Sichuan, China \\ *Corresponding Author: Zhang Zhengjie
}

Keywords: new generation of migrant workers, labor shortage, pay system, incentive

\begin{abstract}
The new generation of migrant workers plays an important role in the economic development and social progress of China. They accelerate the process of the reform and opening up, promote the urbanization, change the mode of economic development, and advance the development of rural agriculture. The profound understanding of the new generation of migrant workers' characteristics and problems is the key to solve the problems of the new generation of migrant workers. Based on the survey, this paper analyzes the characteristics of the new generation of migrant workers and the problems they face to provide the incentive countermeasures for the new generation of migrant workers.
\end{abstract}

\section{Introduction}

On January 31, 2010, the State Council issued the 2010 Central No.1 Document "on the increase of the intensity of urban and rural development, further consolidate the basis of agricultural and rural development certain opinions" which firstly used the formulation of "the new generation of migrant workers". The document requested to take pointed measures to solve the problems of the new generation of migrant workers, so that the new generation of peasant workers' urbanization. As a sign, China's migrant workers into a new era of comprehensive promotion, these enough to show that the new generation of migrant workers has aroused the attention of our country.Migrant workers are a new type of labor force in the process of reform and opening up, which is an important force in the main body of modern industrial workers and the construction of modernization in China. In recent years, the new generation of migrant workers has been more and more concerned by the Party, government and the community.

There are many factors that affect the turnover or willingness of the new generation of migrant workers, but there is no doubt that the salary is the most important factor. Compensation is the basis for attracting, retaining, motivating and condensing talents, fully and continuously exerting their ability and realizing the sustainable development of enterprises. The reasonable and effective compensation system can stimulate the enthusiasm and initiative of employees, and realize the maximization of employee's income and enterprise benefit, which is to realize the win-win between enterprise and employee. However, in recent years, the emergence of "labor shortage" phenomenonreflected the design of enterprise salary system behind the actual needs and the urgent need to improve.

\section{Concept Definition and Research Summary}

Concept Definition. With the development of China's economy, the new generation of migrant 
workers has been boarded the stage. The new generation of migrant workers mainly refers to the peasants, who were born in 1980s, received the influence of education and modern information and had a certain degree of openness from psychological and thinking perspectives. The wage is the main source of income for the agricultural household population in cities. "Shortage of migrant workers" phenomenon main reasons: first, the national policy reasons: increasing the preferential policy, effectively reducing the burden on farmers, to mobilize the farmers returning farming enthusiasm, the western region labor - intensive enterprises, increased demand for labor, for the transfer of labor to create the conditions. Some migrant workers to consider the cost of living in the city as well as the level of wages, more willing to stay at home, migrant workers demand for regional transfer. Secondly, enterprises reason: the coastal economy area labor intensive industry, the demand for the general labor force, to obtain high profits, the use of wages is not reasonable. Finally, the reasons for the migrant workers: the low pay levels and high cost of living cannot match. They cannot adapt to the working environment.

Research Summary. The research achievements of migrant workers in foreign countries are several labor migration models in the field of development economics. Domestic migrant workers have conducted a lot of research, such as the employment discrimination of migrant workers, migrant workers, social security research, etc. But because of the new generation of migrant workers is a new group, the study of the new generation of migrant workers is not enough, especially for the study from the salary system of the new generation of migrant workers.

\section{Current Situation Analysis of New Generation of Migrant Workers}

Compared with the older generation of migrant workers, the new generation of migrant workers has undergone the significant changes in the concept of the world. The main change is to enjoy the modern life, to strengthen the rights awareness and citizenship, to highlight the strong individual standard, the value of their publicity etc. Due to improve the overall quality of the re understanding of the value of their own, they began to realize the "equivalent exchange" and "distribution according to work." The new generation of migrant workers in the 80 and 90 the young people in the 1990s, after the reform and opening up new ideas into the open degree of social China increased significantly. They have grown up with the new idea of implantation, which makes them in character showed a constant pursuit of innovation and development. The new generation of migrant workers has stronger self-consciousness and right consciousness, pay attention to the dignity of labor, to achieve the greatest degree of self-value. In terms of political status and social status, the legitimate rights and interests, respect for personality, schooling of children, social security and other demands are more and more strong. Back in the early industrialization of the United Kingdom, located in remote rural areas of British business owners is by focusing on workers' social welfare to attract workers and maintain its stability. Chinese enterprises also mostly use the advanced enterprise incentive theory to improve the enthusiasm of migrant workers. But according to the principle of contradiction particularity, for each industry incentive mode is very different, cannot be generalized. Under the current social background, enterprises have realized importance to encourage migrant workers, but most of them are incentive mechanism based on the lower satisfaction, many companies focus only on staff to enhance material conditions, while ignoring the spirit incentive for employees. Business managers should be aware of that it is the best way to retain employees to meet the employees'spirits.

\section{Existing Problems of Pay Management in Western China Enterprises}


Serious Condition of Suspending Employees' Salaries.In recent years, more and moredeliberately suspending the wages of migrant workers have happened. However, the reason is not the insufficient funds to pay, but the top leaders' deliberate suspending. They hold is a migrant workers have little culture, limited technical capacity, lack of awareness of rights protection, if a taste of debt collection, and finally brought about the outcome is the unemployment, for migrant workers undoubtedly arrears of wages than more serious, so the deliberate arrears of appears. Wage arrears not only give migrant workers brought economic losses and mental anguish, also brings bad influence on the normal social and economic order, the negative impact seems to be growing. The way can be described as all sorts of strange things. Because of this, in the process of claiming for wage, murder and other violent incidents have occurred, making a bad impact on society.

Cannot Meet the Immaterial Reward.The work environment, the labor intensity, the life quality and the spare-time spending are not satisfying. The new generation of migrant workers cannot achieve the respect of others. They are suffering dual damages of spirit and material.

Unscientific Salary System. At present, the wages of migrant workers are generally distributed in two calculation methods. One is based on hours, and the other is calculated by the number of days. But the enterprise pay the wages in the day calculation method, the workers often have to work at least ten hours a day. The low welfare and the imperfect insurance system cannot arouse the migrant workers motivation.

\section{Incentives Countermeasures of New Generation of Migrant Workers in Western China}

Emotions Countermeasures. It is necessary to enhance communicationwith the employees. As an important means to pay employees value and motivate staff, enterprises must make their own salary system, with employees turning up the mood. Mainly includes the following aspects: widening release channel, so that employees in a timely and effective access to employment information to improve staff confidence. To improve the working environment and improve the lodging and food conditions is important. To attach importance to the construction of enterprise culture and adhere to the "people-oriented" concept is important. Training migrant workers of the new generation of ownership and responsibility, dedication and cooperation struggle of the team spirit, the majority of employees generally enhanced "sharing weal and woe" ideology. We should form a unity cooperation and strenuous upward good atmosphere in the enterprisesto provide powerful spiritual motivation and cultural support for the sustainable development of enterprises.

Salaries Countermeasures. We should ensure the fairness of salary and make the employees understand the value of compensation. Then, the incentive compensation system should be established to arouse theemployees' motivation, fully mobilize the enthusiasm of the staff. Improve the distribution system, the introduction of competition mechanism, more pay for more work, the high labor intensity and labor length and strength corresponding to the labor remuneration. To ensure the fairness of compensation, so that employees understand the value of compensation, compensation to understand the variability. In order to mobilize the enthusiasm of the staff, promote the improvement of the performance of enterprises. We also should improve the salary system, optimize the structure of the salary, and pay the salaries timely.

Adaptation Measures of Emotions and Salaries. We should achieve the goal of adaptation of emotions and salariesso that employees understand the relationship between the pay and the post. Enterprises and government departments should proceed from the following several points. The first step is to promote industrial restructuring and upgrading, rather than rely on low labor costs to obtain profit. Enterprises should know to rely on low labor costs to obtain profits era has gone, and strive to improve employee benefits keep people, to promote industrial restructuring and upgrading 
of profit, to accelerate the reform of the household registration system. Give the new generation of migrant workers and the same treatment, including the same political participation rights, etc. The second step is to increase the investment of vocational education and training, and comprehensively improve the comprehensive quality of the new generation of migrant workers. We should increase efforts to training of migrant workersfor the majority of migrant workers. Finally, the enterprises should abide by the labor contract law to promote the equal employment, the decent employment and the stable employment of migrant workers to realize individual and enterprise mutual winning.

\section{References}

[1] Hu Yuebin, Analysis of current "labor shortage" causes and countermeasures in China, J., Journal of Nanchang College of Education, 2010, (04):7-8.

[2] Yao Xianguo, Fang Yangchun, Literature Review of Studies on Pay System Effectiveness, J., Journal of Zhejiang University(Humanities and Social Sciences), 2005, 35(2): 74-81.

[3] Xu Ying, Problems of New Generation Migrant Workers from thePerspective of Social Discrimination, J., Asian Agricultural Research, 2011, 3(4): 91-94.

[4] LiXiaohong, StudyontheSolutionsofNewGenerationofMigrantPeasant Workers’Employment Problem, D., ShanxiUniversity, 2010. 